\section{A) Check for updates}

Cite this: Nanoscale, 2021, 13, 18684

\title{
Broad-spectrum nanoparticles against bacteriophage infections $\uparrow$
}

\author{
Łukasz Richter, ${ }^{a}$ Karolina Paszkowska, ${ }^{\mathrm{b}}$ Urszula Cendrowska, ${ }^{\mathrm{a}}$ Francesca Olgiati, ${ }^{\mathrm{a}}$ \\ Paulo Jacob Silva, ${ }^{a}$ Matteo Gasbarri, (iD ${ }^{a}$ Zekiye Pelin Guven, ${ }^{a}$ Jan Paczesny ${ }^{\mathrm{b}}$ and \\ Francesco Stellacci (D) *a,c
}

\begin{abstract}
Viral infections caused by bacteriophages, i.e., viruses that kill bacteria are one of the most dangerous and common threats for bacteria-based bioreactors. More than $70 \%$ of biotechnology companies have admitted to encountering this problem. Despite phage infections being such a dangerous and widespread risk, there are no effective methods to avoid them to date. Herein, we present a novel technology based on nanoparticles that irreversibly deactivates bacteriophages and is safe for bacteria. Our method allows for the unsupervised protection of bacterial processes in the biotechnology industry. Gold nanoparticles coated with a mixture of negatively charged 11-mercapto 1-undecanesulfonic acid (MUS) and hydrophobic 1-octanethiol (OT) ligands are effective at deactivating various types of Escherichia coli-selective phages: T1, T4, and T7. The nanoparticles can lower the titer of phages up to 2 and 5 logs in 6 and $24 \mathrm{~h}$ at $50{ }^{\circ} \mathrm{C}$, respectively. A comparative analysis of nanoparticles with different ligand shells illustrates the importance of the combination of negatively charged and hydrophobic ligands that is the key to achieving a good inhibitory concentration $\left(E_{50} \leq 1 \mu \mathrm{g} \mathrm{mL}^{-1}\right.$ ) for all tested phages. We show that the nanoparticles are harmless for the commonly used bacteria in industry Escherichia coli and are effective under conditions simulating the environment of bioreactors.
\end{abstract}

Received 29th July 2021

Accepted 6th October 2021

DOI: $10.1039 / \mathrm{d} 1 \mathrm{nr} 04936 \mathrm{~d}$

rsc.li/nanoscale dangerous and common factors is infections caused by bacteriophages, i.e., viruses attacking and killing bacteria. In the dairy industry, $1 \%$ to $10 \%$ of batches of products are lost to phages. ${ }^{1}$ More than $70 \%$ of biotechnology companies have admitted to encountering this problem. ${ }^{1}$

Even a few virions (viral particles) might contaminate a whole industrial production vessel and produce up to $10^{13}$ progeny phages per $\mathrm{mL}$ within a few hours. ${ }^{2}$ Hundreds of new virions are released from a single infected bacterium within tens of minutes, thus the fight against phage-based contaminations is extremely difficult. Moreover, some phages can survive high temperatures (e.g., boiling), pasteurization, organic solvents, drying, and even vacuum. ${ }^{3}$

Despite phage infections being such a dangerous and widespread risk, to date, there are no effective methods to avoid and fight them. Although some approaches have been proposed, they are limited by being only preventive (rotation of bacterial strains ${ }^{4}$ ), not very effective (thermal, ${ }^{5}$ UV radiation ${ }^{4}$ ), unsuitable for large volumes (filtration ${ }^{6-8}$ ), expensive and overly specific (engineered proteins, ${ }^{9-11}$ phage-resistant mutants ${ }^{12}$ ) or harmful for bacteria (biocides ${ }^{5,13}$ ).

Nanoparticles have a constantly growing number of applications in biological systems and they were also used to deactivate phages. ${ }^{14-19}$ Approaches based on silver, ${ }^{20-24}$ copper 
oxide, ${ }^{22,24,25}$ titanium dioxide ${ }^{26,27}$ and iron-nickel ${ }^{28}$ nanoparticles have been proven to be effective in phage deactivation. However, all of them share one of the two possible mechanisms of action: production of toxic silver or copper ions $^{20-22}$ or generation of reactive oxygen species (ROS). ${ }^{26,27}$ Both mechanisms are also effective in the deactivation of bacteria $^{29}$ and therefore cannot be used to selectively protect bacteria from phages in the biotechnology industry. Only nanoparticles effective in phage deactivation and at the same time harmless for bacteria can be used in such applications.

Currently, the most commonly applied solution to a bacteriophage infection is shutting down the reactor and thoroughly disinfecting it, which is an operation that takes days and comes with a significant economic burden. The ideal solution should provide effective eradication of phages before infection of the first bacteria. Such an approach would prevent the most dangerous and difficult scenario: a massive outbreak that leads to large volumes with high concentrations of phages.

Here we present anti-phage gold nanoparticles that can deactivate bacteriophages and at the same time remain harmless to the bacteria. Negatively charged nanoparticles coated with a mixture of 11-mercapto 1-undecanesulfonic acid (MUS) and hydrophobic 1-octanethiol (ОT) first attach to phages through electrostatic forces, and then virions are deactivated by irreversible local distortions caused by hydrophobic interactions (Fig. 1). MUS: OT nanoparticles are effective in conditions similar to the industrial bioreactors and can prevent the infection after just $1 \mathrm{~h}$ of the preincubation step.

\section{Results and discussion}

Our approach to deactivate phages is based on gold nanoparticles coated by a mixture of negatively charged MUS and hydrophobic OT ligands. MUS : OT nanoparticles were already proven to be broad-spectrum antiviral agents against eukaryotic viruses. ${ }^{30}$ We studied nanoparticles with final ratios of MUS to OT ligands: 70:30 and 85:15 (Fig. 2a and b). Final ratios of ligands were calculated from NMR, as provided in the ESI. $\dagger$ Nanoparticles were designed to provide deactivation by initial electrostatic attraction followed by hydrophobic interactions causing local irreversible distortions. Long and flexible ligands provide multivalent contact between charges of the nanoparticles and bacteriophage surface. Additionally, we examined positively charged nanoparticles, coated with TMA (Fig. 2c). As a control, non-charged particles with tetra(ethylene glycol) $\left(\mathrm{EG}_{4}\right)$ ligands were also tested (Fig. 2d). We kept a similar size of particles and length of ligands to directly compare the influence of different nanoparticles on phage virions (Table $\mathrm{S} 1 \dagger$ ).

\section{Influence of nanoparticles on phages and bacteria}

Escherichia coli is not only one of the most commonly used bacteria in the biotechnology industry, but it is also the beststudied model bacterium. ${ }^{31,32}$ It is the most common bacterial species used for the industrial production of biopharmaceuticals and it is also the second most common system to be used for such a purpose in general. ${ }^{33}$ Thus, we aimed to effectively deactivate $E$. coli-specific phages representing three different

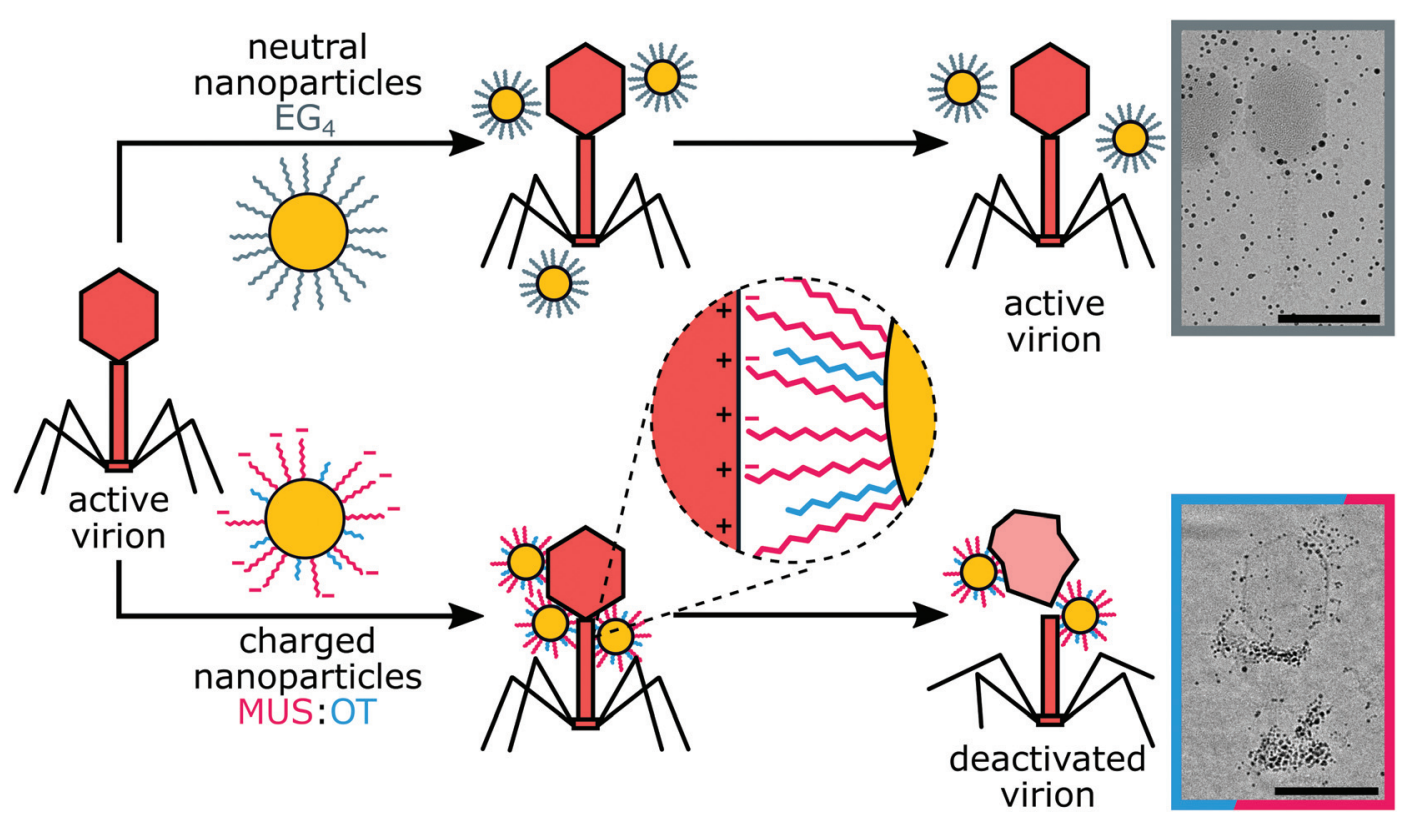

Fig. 1 Scheme of the anti-phage activity of the prepared charged nanoparticles. The particles first attach to phages through electrostatic interactions, and then virions are deactivated by irreversible local distortions. Electrically neutral particles remain inert for bacteriophages. Cryo-TEM images present the deactivating effect of negatively charged nanoparticles coated with a mixture of 11-mercapto 1-undecanesulfonic acid (MUS) and hydrophobic 1-octanethiol (OT) on T4 phage (blue-magenta box) and lack of such interactions between T4 bacteriophages and non-charged nanoparticles coated with tetra(ethylene glycol) $\left(\mathrm{EG}_{4}\right)$ (grey box) (scale bars, $100 \mathrm{~nm}$ ). 
a) MUS:OT
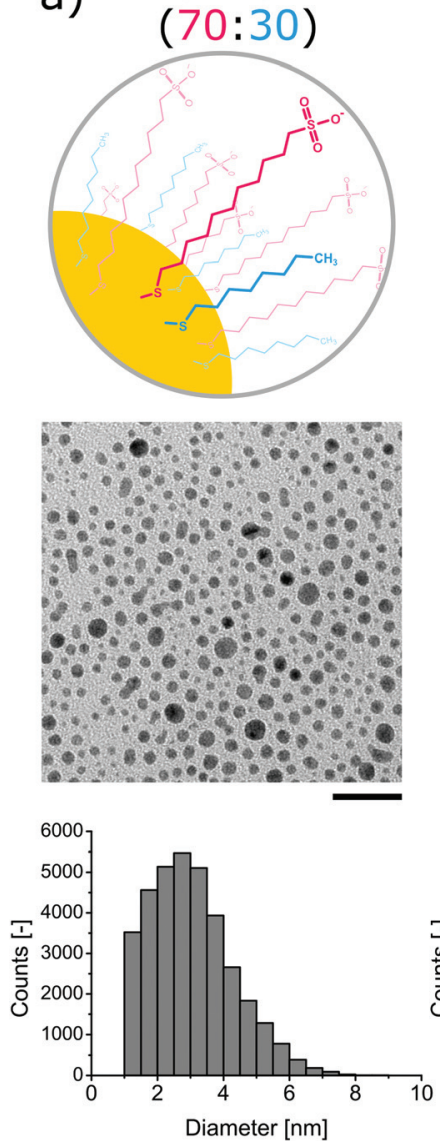
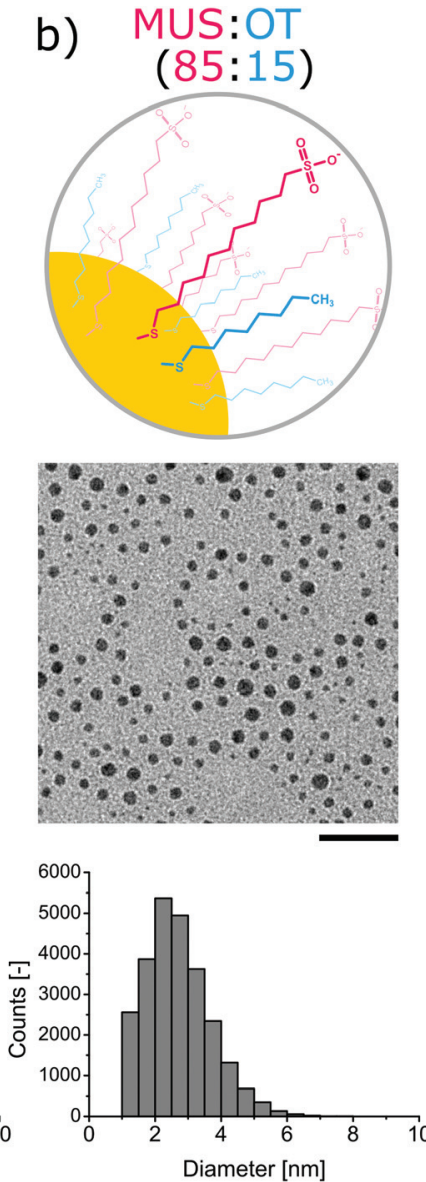
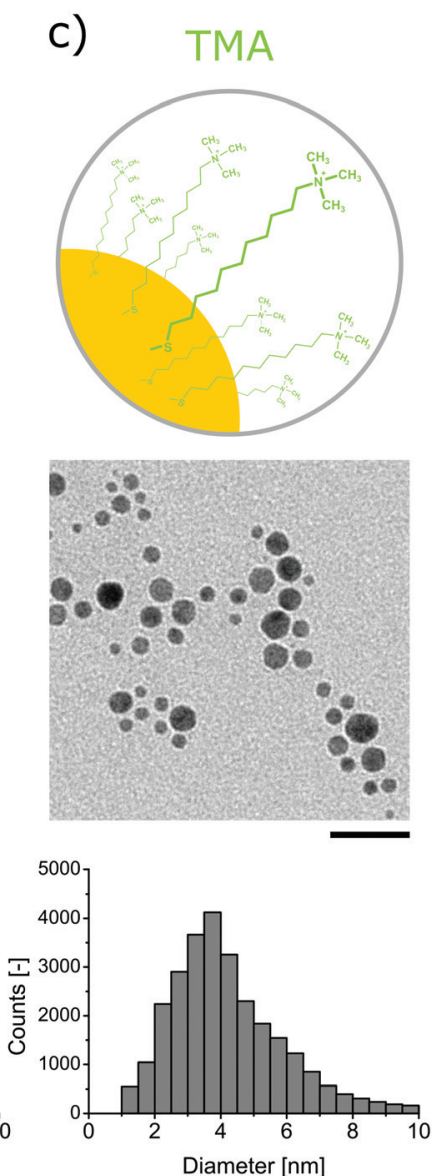
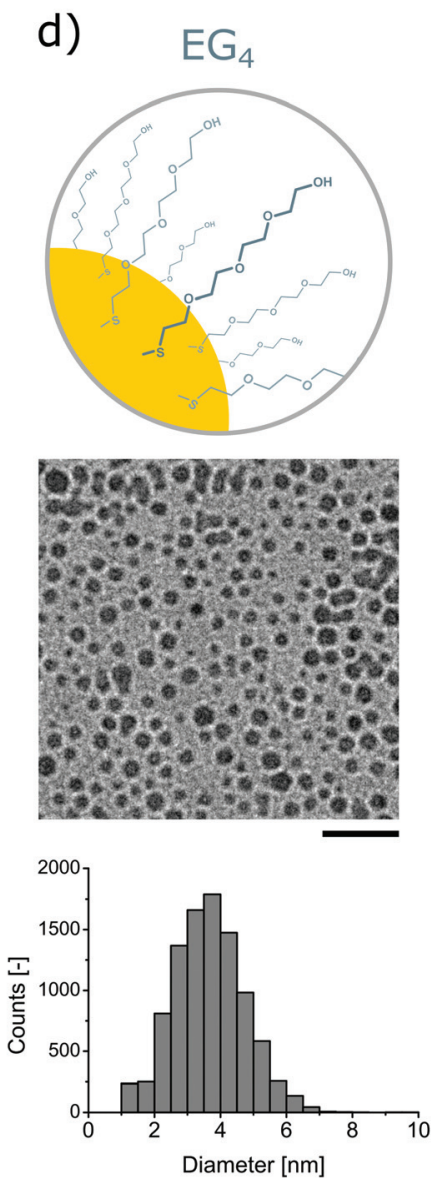

Fig. 2 Gold nanoparticles used in this study. Charge of nanoparticles was adjusted by coating with various ligands: (a) mixture of 70\% 11-mercapto 1-undecanesulfonic acid (MUS) and 30\% hydrophobic 1-octanethiol (OT); (b) mixture of 85\% MUS and 15\% OT; (c) N,N,N-trimethyl(11-mercaptoundecyl)ammonium (TMA); (d) 2-(2-(2-(2-mercapto-ethoxy)ethoxy)ethoxy)ethanol (EG4). For each studied type of nanoparticles, the size distribution and representative TEM image are presented. All particles had a similar size of around $3 \pm 1 \mathrm{~nm}$ (scale bars, $20 \mathrm{~nm}$ ).

families: T1 type from Siphoviridae (T1-like phages are causing the majority of $E$. coli fermentation failures ${ }^{34}$ ), T4 type from Myoviridae (one of the best known and well-studied phages ${ }^{35}$ ) and T7 type from Podoviridae. All of them share a head-tail structure that is characteristic for more than $95 \%$ of all known bacteriophages, ${ }^{36}$ thus the obtained results can be applied to other industrial bacteria-based systems.

As a first test, we incubated bacteriophages with $0.5 \mathrm{mg}$ $\mathrm{mL}^{-1}$ of nanoparticles in TM buffer over three days and analysed the changes in the number of active phages in time (Fig. 3a). We applied two temperatures: $37^{\circ} \mathrm{C}$ (optimal for bacteria growth) and $50{ }^{\circ} \mathrm{C}$, a slightly increased temperature that is still accepted in many industrial procedures. Since phage titer measurements include serial dilution steps, all observed deactivation effects are irreversible (i.e., virucidal).

The most efficient deactivation of phages at both temperatures was obtained for TMA nanoparticles. Drops of active phages: $2 \operatorname{logs}$ for T7, $3 \log$ s for T4 and up to $6 \operatorname{logs}$ for T1, were visible already after the first few hours (Fig. 3). Interestingly, an increase in the temperature from $37^{\circ} \mathrm{C}$ to $50{ }^{\circ} \mathrm{C}$ did not change the magnitude of the observed effects. The strongest deactivation was obtained for $\mathrm{T} 1$, where no active virions were visible after 6 hours of incubation. This is in line with the literature since cationic compounds were previously reported to be effective in phage deactivation..$^{37}$ However, TMA nanoparticles turned out to be unstable in LB medium and toxic against bacteria $E$. coli (Fig. S $3 \uparrow$ ), ${ }^{38}$ thus, they were excluded from further tests.

Both studied MUS : OT nanoparticles were effective against all tested types of phages (Fig. 3). At $37{ }^{\circ} \mathrm{C}$ no effect was observed, and a higher temperature was required to trigger the deactivation. At $50{ }^{\circ} \mathrm{C}$ MUS : OT nanoparticles decreased the titer of phages by up to two logs in $6 \mathrm{~h}$. After $24 \mathrm{~h}$ exposure, the decrease was up to 5 logs. To determine the lowest amount of nanoparticles required for effective deactivation, we performed dose-response tests for the best performing nanoparticles (MUS:OT, $85: 15$ ) against all three types of phages (Fig. 3b). Bacteriophages were incubated with various concentrations of nanoparticles for $24 \mathrm{~h}$, and then the activity of the phages was evaluated. The obtained $\mathrm{EC}_{50}$ values (i.e., effective concentration deactivating $50 \%$ of phages) for MUS:OT $(85: 15)$ nanoparticles were in a similar range of 0.2 to $1.2 \mu \mathrm{g}$ $\mathrm{mL}^{-1}$ for all types of bacteriophages. Since $\mathrm{EC}_{50}$ depends on 
a)
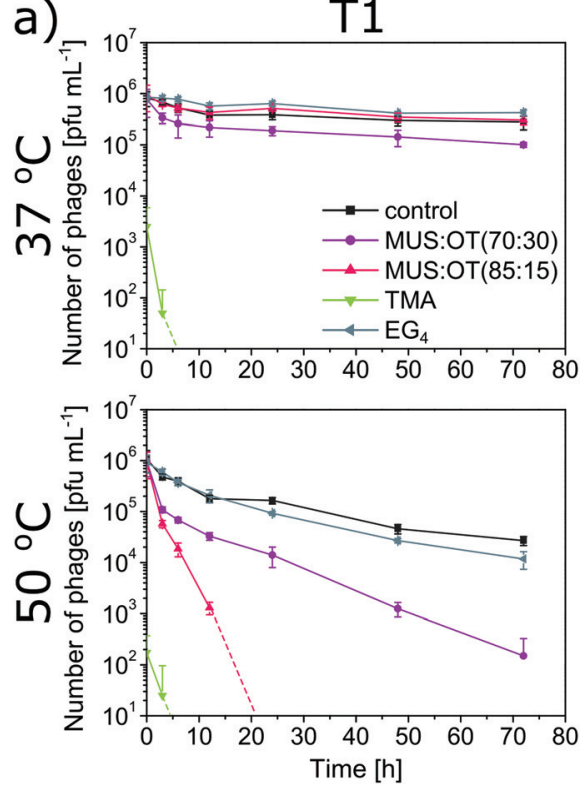

b)

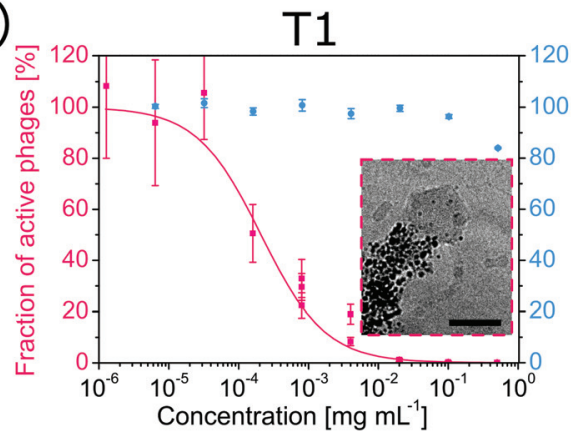

T4
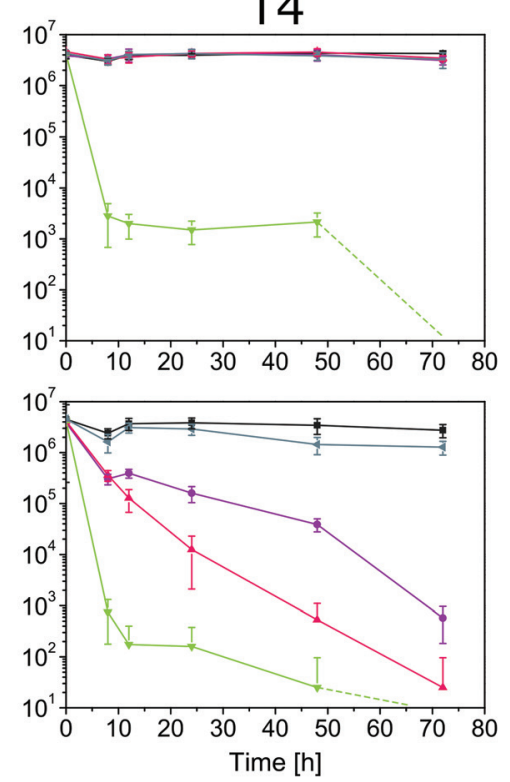

T4

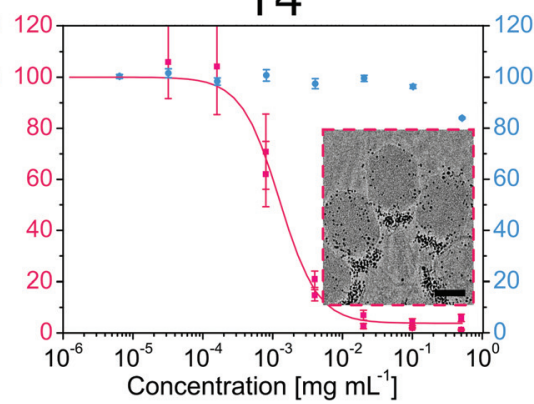

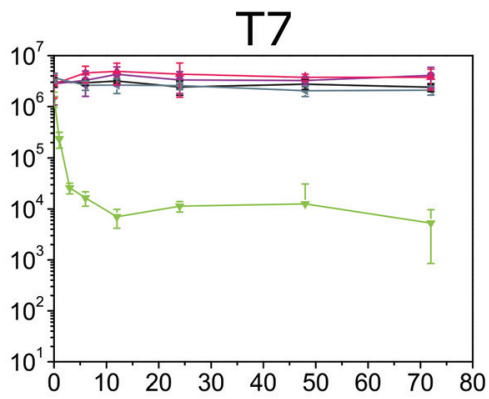

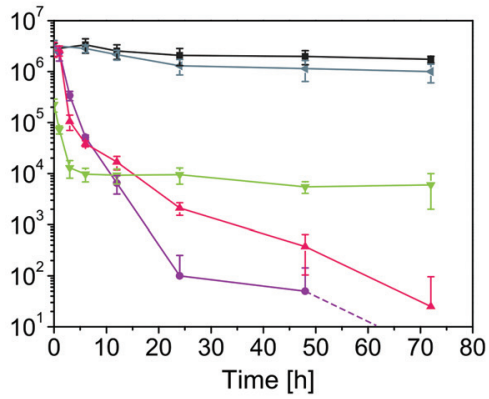

Fig. 3 Comparison of the anti-phage effect of the studied nanoparticles. (a) Three types of phages: T1, T4, and T7 were incubated over few days with $0.5 \mathrm{mg} \mathrm{mL}^{-1}$ of various nanoparticles at $37^{\circ} \mathrm{C}$ or $50^{\circ} \mathrm{C}$. All charged nanoparticles had a deactivating effect against every tested type of bacteriophage. Used as control, electrically neutral nanoparticles coated with EG4 were inert for bacteriophages, which confirmed the importance of electrostatic interactions. (b) Dose-response of MUS: OT $(85: 15)$ nanoparticles on three types of phages. Nanoparticles were incubated with phages for $24 \mathrm{~h}$ at $50{ }^{\circ} \mathrm{C}$. Obtained $\mathrm{EC}_{50}$ equaled $0.21 \mu \mathrm{g} \mathrm{mL}^{-1}, 1.23 \mu \mathrm{g} \mathrm{mL}$, and $0.32 \mu \mathrm{g} \mathrm{mL}^{-1}$ for T1, T4, and T7 phages, respectively. Additionally, no antibacterial effect was observed against bacteria $E$. coli $\left(E_{50}>0.5 \mathrm{mg} \mathrm{mL}^{-1}\right.$ ) (scale bars, $\left.50 \mathrm{~nm}\right)$.

the time of the exposition, we also checked the $\mathrm{EC}_{50}$ of MUS: OT ( $85: 15)$ nanoparticles against phage T4 for various times of incubation (Fig. 4). $6 \mathrm{~h}$ of incubation was enough to obtain an $\mathrm{EC}_{50}$ of $12.1 \mu \mathrm{g} \mathrm{mL} L^{-1}$ (i.e., $80 \mathrm{nM}$ ) and extending the time to $24 \mathrm{~h}$ resulted in an $\mathrm{EC}_{50}$ as low as $1.7 \mu \mathrm{g} \mathrm{mL} \mathrm{L}^{-1}$ (i.e., 11 nM). Finally, we should add that despite being effective against phages T1, T4, and T7, MUS : OT nanoparticles did not interact with other types of phages - spherical phages MS2 that lack the complex head-tail structure (Fig. S4†).

To check the importance of the electrostatic interactions, we used nanoparticles coated with ligands that did not bear a charged group. We could not use non-charged nanoparticles covered only with aliphatic chains since they are not soluble in water. Thus, we used nanoparticles covered with tetra(ethylene glycol) chains, which are also not charged and are soluble in the water environment. Non-charged $\mathrm{EG}_{4}$ nanoparticles showed no effect in all analysed cases, confirming the importance of the electrostatic forces.
To evaluate the significance of the hydrophobic interactions, we tested nanoparticles coated only with MUS ligands (Fig. S5 $\dagger$ ). Lack of OT ligands decreased the hydrophobicity of MUS nanoparticles. As a result, MUS nanoparticles did not deactivate any of the three types of phages (Fig. S6†) either at $37{ }^{\circ} \mathrm{C}$ or $50{ }^{\circ} \mathrm{C}$. These experiments show that the addition of hydrophobic interactions provided by OT ligands is crucial for effective deactivation.

The deactivation test was complemented with toxicity studies against bacteria $E$. coli BL21. We found that MUS:OT $(85: 15)$ nanoparticles were inert for tested bacteria, and no influence on their viability was visible in the tested range $\left(\mathrm{EC}_{50}>500 \mathrm{mg} \mathrm{mL}^{-1}\right)$, with a small influence observed only at the highest concentration (Fig. $3 \mathrm{~b}$ and Fig. S7†). Therefore, we showed that MUS:OT nanoparticles have two properties crucial for the protection of the bacteria-based bioreactors: effective at bacteriophage deactivation and at the same time remain harmless for bacteria. 

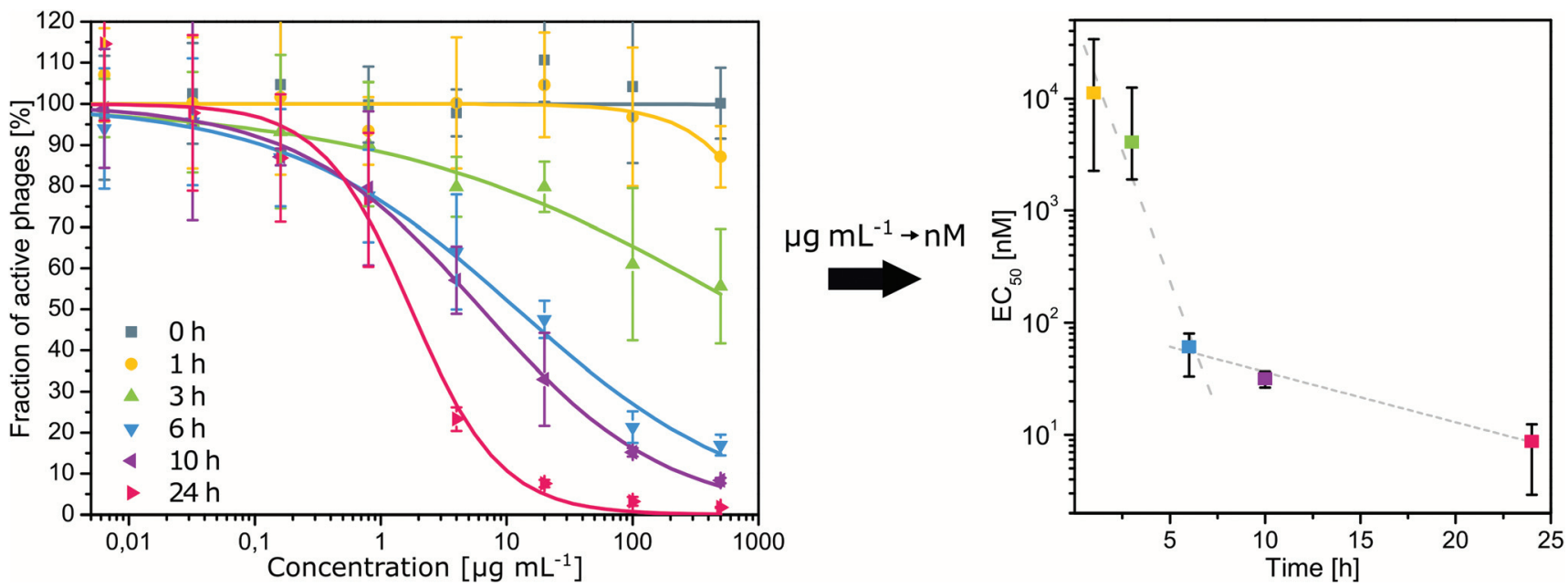

Fig. 4 Dose responses of nanoparticles MUS : OT $(85: 15)$ against phage T4 for various times of incubation. The right panel presents the dependency of calculated $\mathrm{EC}_{50}$ values on the time of incubation. The molecular weight of nanoparticles was $200 \mathrm{kDa}$. Error bars on the right panel represent the $95 \%$ confidence interval of fitted $\mathrm{EC}_{50}$ values.

\section{Analysis of the mechanism of action}

To better understand interactions between phages and nanoparticles, we focused on the model pair: phage T4 (well-known and studied phage) and best-performing nanoparticles MUS : OT (85:15). Bacteriophage T4 has a head-tail structure that is a characteristic of more than $95 \%$ of all known bacteriophages, ${ }^{36}$ and consists of a $115 \mathrm{~nm}$-long, $85 \mathrm{~nm}$ wide head, and a $100 \mathrm{~nm}$-long, 21-diameter contractile tail terminated with a 46 nm-diameter baseplate and six 145 nm-long fibres attached to the baseplate (Fig. 5a). The mature virus is composed of over forty different types of structural proteins, among which eighteen are exposed to the external environment. ${ }^{35,39}$ The majority of these structural proteins are negatively charged in $\mathrm{pH}$ around 7 (i.e., their $\mathrm{pI}<7$ ), with the exception of the ends of fibres, in which $\mathrm{pI}$ is higher than 7 (Fig. 5a). Such distribution of charges of phage virions was developed in the process of evolution. Positively charged fibres a)

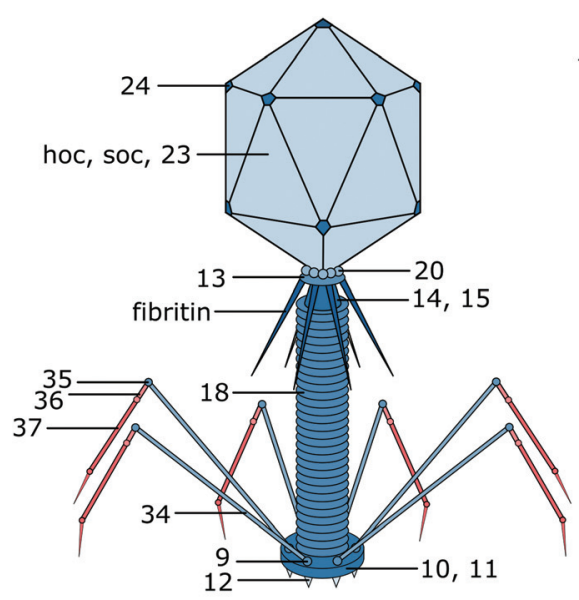

b)

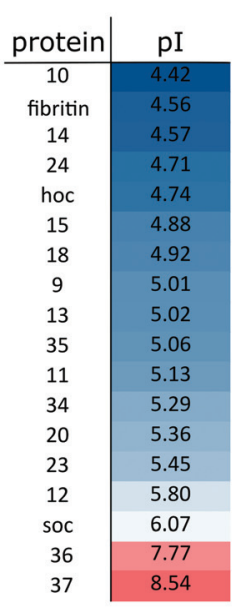

$37^{\circ} \mathrm{C}$

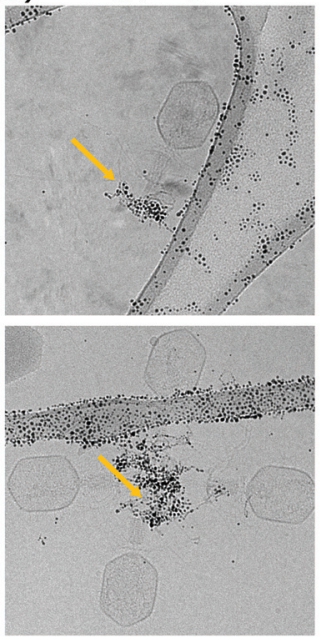

c) $\quad 50^{\circ} \mathrm{C}$

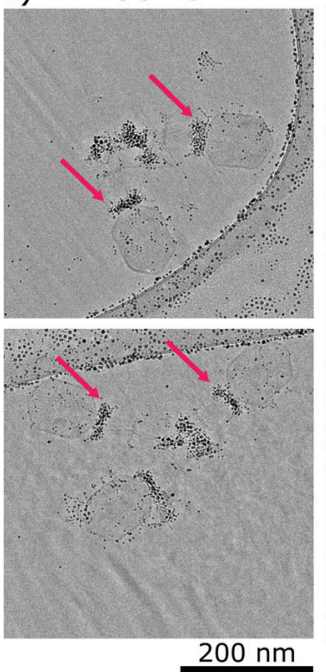

d)

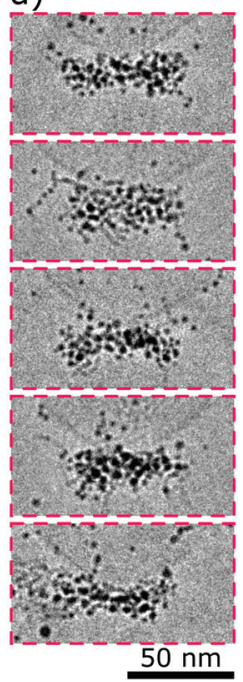

Fig. 5 (a) Structure of bacteriophage T4. Red or blue colors represent a charge at $\mathrm{pH} 7.4$ that is positive or negative, respectively. The table presents the isoelectric point (pl) of structural proteins. Panels on the right: cryo-TEM analysis of the interaction between T4 phages and MUS : OT (85:15) nanoparticles at various temperatures. T4 bacteriophages were incubated with $0.1 \mathrm{mg} \mathrm{mL}^{-1}$ of nanoparticles at (b) $37{ }^{\circ} \mathrm{C}$ and (c) $50{ }^{\circ} \mathrm{C}$ for $24 \mathrm{~h}$. Panel (d) presents magnified parts of cryo-TEM images from panel (c). At lower temperatures, negatively charged nanoparticles interacted mainly with positively charged fibers of bacteriophages (yellow arrows). Unexpectedly, at higher temperatures, nanoparticles decorated collars of T4 phages (magenta arrows). As we have shown in Fig. 3, the latter type of interaction caused the deactivation of phages. 
are electrostatically attracted to bacteria, which have a negatively charged surface. Detailed information about all analysed proteins is provided in Table S2. $\dagger$

We analysed the interactions of phages and nanoparticles using cryo-TEM imaging. At $37{ }^{\circ} \mathrm{C}$ MUS:OT nanoparticles adsorbed mostly on the positively charged fibres of the bacteriophages (Fig. 5b). These interactions were already visible after 20 minutes of incubation (Fig. S8†). As shown in Fig. 3a, such adsorption does not cause effective deactivation of bacteriophages. In comparison, positively charged TMA nanoparticles attached under these conditions to negatively charged tails of the T4 phage virions, and neutral $\mathrm{EG}_{4}$ nanoparticles did not interact with $\mathrm{T} 4$ phages at all (Fig. 6). Thus, we confirmed that at $37^{\circ} \mathrm{C}$, the interactions between phages and nanoparticles could be predicted based on electrostatic forces between averaged charges of phage proteins (represented by their isoelectric point) and charges of nanoparticles.

At a higher temperature of $50^{\circ} \mathrm{C}$ we observed that MUS : OT particles bind to the phages in other parts, i.e., collars and heads (Fig. 5c and Fig S9†). Nanoparticles attach mostly to short fibritin fibres, creating a gold "necklace" visible in cryoTEM images. Attachment of gold nanoparticles to the neck part of bacteriophage T4 seems crucial for effective inhibition and does not match the simple prediction of electrostatic interactions based on overall averaged charges. Almost all proteins are composed of both positively and negatively charged amino acids (Table S2 $\dagger$ ), and thus have many positive and negative patches or cavities with which nanoparticles can interact. ${ }^{40}$ We should stress that these studies are qualitative in nature as in TEM one can never be sure that the imaged viruses were infecting before interacting with the nanoparticles.

\section{Realistic application test mimicking an infected bioreactor}

We tested the best-performing nanoparticles (MUS:OT, $85: 15)$ in the real-life application of protection of bacteria inside a phage-infected bioreactor. We used phage T1, since
T1-like phages are causing the majority of $E$. coli fermentation failures. ${ }^{34}$ First, we incubated $200 \mathrm{pfu} \mathrm{mL}^{-1}$ of $\mathrm{T} 1$ bacteriophages with MUS:OT (85:15) nanoparticles for a given amount of time at $50{ }^{\circ} \mathrm{C}$ to achieve initial deactivation. We tested two cases: (a) incubation with $20 \mu \mathrm{g} \mathrm{mL} \mathrm{m}^{-1}$ of nanoparticles for $12 \mathrm{~h}$ and (b) incubation with $100 \mu \mathrm{g} \mathrm{mL} \mathrm{m}^{-1}$ of nanoparticles for $1 \mathrm{~h}$. Then an inoculum of bacteria $E$. coli BL21 was added to such a mixture, and bacteria were cultured at $37^{\circ} \mathrm{C}$ in LB medium with mixing. As controls, samples with normally growing bacteria and samples contaminated with non-treated phages were prepared (Fig. 7a). In bacterial cultures infected with phages, the growth of bacteria stopped after $1.5 \mathrm{~h}$, and all bacteria were infected and killed. However, in samples protected with anti-phage nanoparticles, no phage infection was visible, and bacterial culture grew as in control experiments (Fig. 7b). The $1 \mathrm{~h}$ preincubation step was enough to deactivate all phages and provide a protecting effect of nanoparticles. Thus, in practical application, after the addition of nanoparticles to the bioreactor, the only requirement would be to perform a short preincubation before starting the main bioreactor process.

\section{Cytotoxicity and practical applications}

Utilized MUS:OT nanoparticles were already proven to be non-toxic for eukaryotic cells in both in vitro and ex vivo tests. $^{30}$ Nonetheless, to check the cytotoxicity of the nanoparticles used in this study, we performed MTS assay on Vero cells after $24 \mathrm{~h}$ of incubation with all four types of nanoparticles (Fig. 8). No cytotoxic effect of both MUS : OT and PEG nanoparticles was visible up to a concentration $1000 \mu \mathrm{g} \mathrm{mL} \mathrm{m}^{-1}$. For comparison, $\mathrm{EC}_{50}$ of nanoparticles MUS:OT $(85: 15)$ against bacteriophages was in the range of $1 \mu \mathrm{g} \mathrm{mL}^{-1}$. Additionally, as expected, positively charged TMA nanoparticles were toxic against tested mammalian cells.

Another important issue is the removal of the nanoparticles from the final product in downstream processes. Due to the

MUS:OT

$(85: 15)$

TMA

$\mathrm{EG}_{4}$
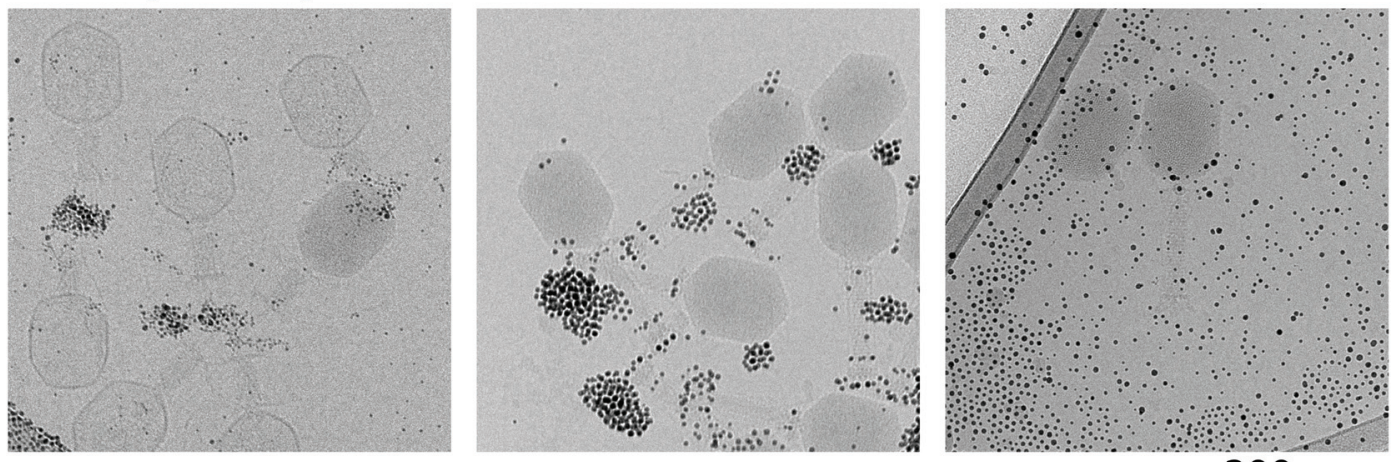

$200 \mathrm{~nm}$

Fig. 6 Interactions of various types of nanoparticles with bacteriophages T4 at $37^{\circ} \mathrm{C}$. Negatively charged nanoparticles MUS : OT (85: 15) attached to positively charged fibers of phages, positively charged TMA nanoparticles covered negatively charged tails of phages, whereas neutral EG4 nanoparticles didn't interact with virions at all. 


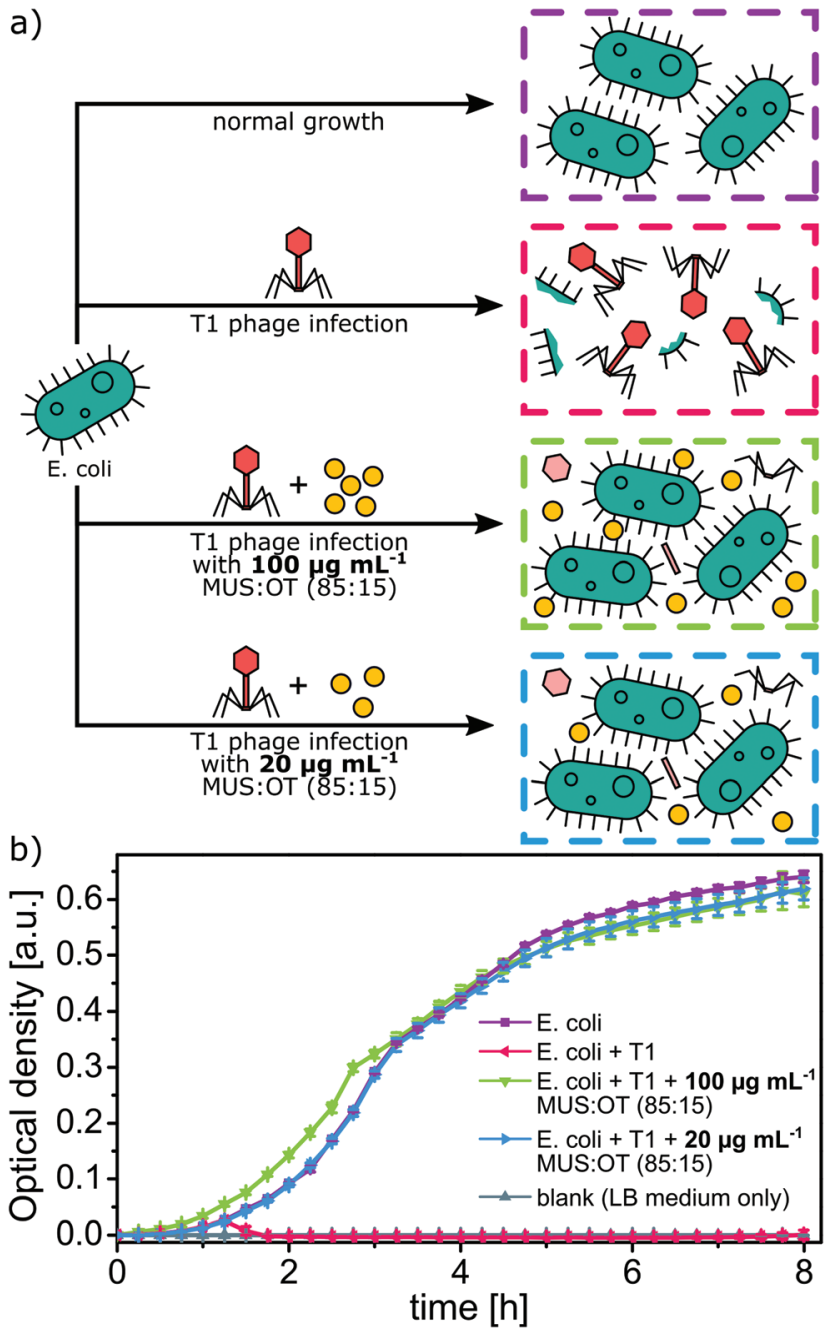

Fig. 7 Protective effect of nanoparticles in the practical application of bacterial culture contaminated with bacteriophages. (a) Four investigated cases: normal bacterial culture, bacterial growth contaminated with phages, and bacterial culture infected with phages and protected by two different concentrations of anti-phage nanoparticles. (b) 200 pfu $\mathrm{mL}^{-1}$ of bacteriophages T1 was preincubated with MUS: OT $(85: 15)$ nanoparticles, and then the starting amount of bacteria was added. The growth of bacterial cultures was monitored by the measurements of optical density $\left(\mathrm{OD}_{600}\right)$. Contamination of phages caused the eradication of all bacteria. In the case of the application of protective nanoparticles, phages were deactivated, no infection was possible, and bacteria grew normally.

difference in size between nanoparticles $(\sim 3 \mathrm{~nm})$ and bacteria $(\sim 1 \mu \mathrm{m})$, nanoparticles can be easily separated by filtration on $0.45 \mu \mathrm{m}$ filters or centrifugation.

Moreover, downstream processing of bioreactor-based production of biopharmaceuticals involves steps like cell lysis (mechanical or enzymatic), nucleic acid degradation, cell-wall material removal, filtration and final purification via chromatography (e.g., immobilized metal affinity chromatography). ${ }^{41}$ Such a great number of purification steps provide many possibilities for the effective removal of nanoparticles from the final product.

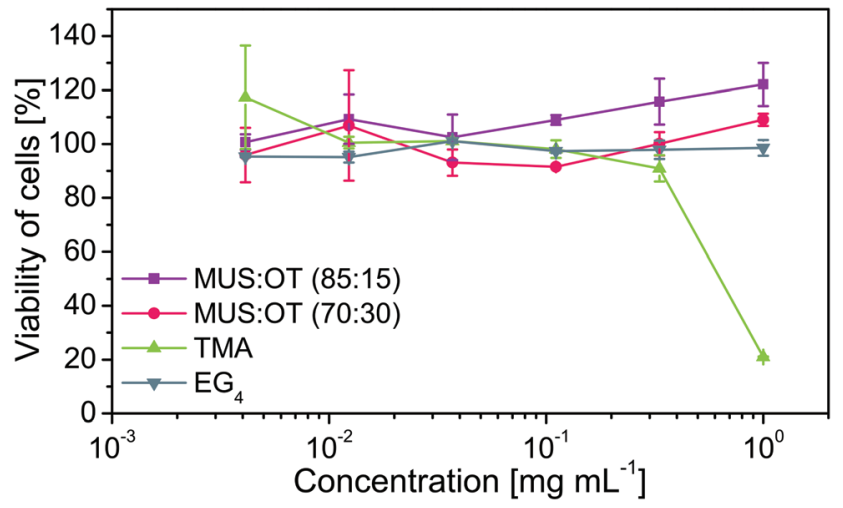

Fig. 8 Cytotoxic effect of nanoparticles on the Vero cell line. Cells were incubated with various concentrations of all four types of nanoparticles for $24 \mathrm{~h}$. Then, MTS assay was used to evaluate their viability.

Finally, the mechanism of deactivation of phages with MUS:OT nanoparticles is based on the interaction with ligands and is independent of the nanoparticle core. Therefore, the developed technology is a first step toward designing better antiphage agents for industrial applications. The idea presented in our study can be in the future transferred to other types of nanoparticles, with cheaper and more biocompatible cores, such as silica or possibly even polymers or biopolymers.

\section{Conclusions}

We believe that the presented approach has the ability to produce safe, non-toxic, and easy-to-apply solutions for the phage problem in the biotechnology industry. To date, nanoparticles designed to deactivate phages were based on the generation of silver/copper ions or ROS - mechanisms which are harmful to all biological species (bacteria, cells, viruses, and phages). Thus, selective protection of bacteria from phages was not possible. The presented solution approaches the problem of phage infection from a completely new perspective. For the first time, technology focusing on the protection of bacteria directly inside the bioreactor is provided. We prepared anti-phage nanoparticles that were effective in the environment of bioreactors and were harmless for bacteria E. coli. The nanoparticles efficiently deactivated all three types of tested phages at reasonable concentrations, including T1, which is the most common cause of failure of E. coli fermentations. The nanoparticles were able to decrease the orders of magnitude of phages within a few hours. We showed that a combination of negatively charged and hydrophobic ligands was the key for effective phage deactivation with good inhibitory concentration $\left(\mathrm{EC}_{50} \leq 1 \mu \mathrm{g} \mathrm{mL}^{-1}\right)$. The best-performing nanoparticles MUS: OT $(85: 15)$ require just a $1 \mathrm{~h}$ preincubation step at $50{ }^{\circ} \mathrm{C}$ to fully deactivate $\mathrm{T} 1$ phages and protect bacteria $E$. coli in an environment similar to the inside of the bioreactor. 


\section{Experimental}

\section{Synthesis of MUS : OT nanoparticles}

The 11-mercapto 1-undecanesulfonic acid (MUS) ligand was synthesized according to the procedure reported by Cendrowska et al. and Guven et al. ${ }^{42,43}$ Nanoparticles (NPs) were synthesized via the method developed by Zheng et al. ${ }^{44}$ later modified by Verma et al. ${ }^{45}$ First, gold salt $\left(\mathrm{HAuCl}_{4} \cdot 3 \mathrm{H}_{2} \mathrm{O}\right.$; $0.9 \mathrm{mmol})$ and both ligands $(0.9 \mathrm{mmol}$ in total $)$ were dissolved in ethanol $(220 \mathrm{~mL})$ and mixed for $15 \mathrm{~min}$. The feed ratio between MUS and 1-octanethiol (OT) ligands was 1:1 and $2: 1$, for MUS:OT $(70: 30)$ and MUS:OT (85:15) nanoparticles, respectively. Then, sodium borohydride $\left(\mathrm{NaBH}_{4}\right.$; $50 \mathrm{mmol})$ dissolved in ethanol $(200 \mathrm{~mL})$ was added dropwise to the mixture upon mixing for over $2 \mathrm{~h}$. The reaction was continued for an additional $24 \mathrm{~h}$. Precipitated nanoparticles were then washed by centrifugation using ethanol and finally purified with MilliQ water on Amicon ${ }^{\circledR}$ Ultra-15 centrifugal filter devices (10k or $30 \mathrm{k}$ NMWL). The particles were then suspended in a small amount of water $(\sim 2 \mathrm{~mL})$ and freeze-dried. The molecular weight of nanoparticles was calculated as shown in the ESI. $\dagger$

\section{Synthesis of TMA nanoparticles}

$N, N, N$-Trimethyl(11-mercaptoundecyl)ammonium

(TMA) ligands and NPs were prepared according to the procedure reported by Cendrowska et $a .^{42}$ To prepare nanoparticles, chloro(triphenylphosphine)gold(I) (0.56 mmol) and the TMA ligand $(1.2 \mathrm{mmol})$ were dissolved in ethanol : toluene mixture $(1: 1,230 \mathrm{~mL})$. After $10 \mathrm{~min}$ of stirring, borane tert-butylamine complex (1.5 mmol) dissolved in an ethanol : toluene mixture $(1: 1 ; 20 \mathrm{~mL})$ was added. The reaction was continued at $125^{\circ} \mathrm{C}$ $(800 \mathrm{rpm})$ for $1.5 \mathrm{~h}$. Afterward, the volume was decreased in a rotary evaporator, which caused the precipitation of NPs. Nanoparticles were then washed by centrifugation using diethyl ether and toluene and finally purified with Milli-Q water on Amicon ${ }^{\circledR}$ Ultra-15 centrifugal filter devices $(10 \mathrm{k}$ or 30k NMWL). The particles were suspended in a small amount of water $(\sim 2 \mathrm{~mL})$ and freeze-dried.

\section{Synthesis of EG4 nanoparticles}

Gold salt $\left(\mathrm{HAuCl}_{4} \cdot 3 \mathrm{H}_{2} \mathrm{O} ; 0.2 \mathrm{mmol}\right)$ and 2-(2-(2-(2-mercaptoethoxy)ethoxy)ethoxy)ethanol $\left(\mathrm{EG}_{4}\right)(0.2 \mathrm{mmol})$ were dissolved in ethanol $(20 \mathrm{~mL})$ and stirred for $15 \mathrm{~min}$. Then, sodium borohydride $\left(\mathrm{NaBH}_{4}, 2.5 \mathrm{mmol}\right)$ dissolved in ethanol $(37.5 \mathrm{~mL})$ was added dropwise to the mixture for over 1 minute. The reaction was continued for an additional $24 \mathrm{~h}$. Next, Milli-Q water $(50 \mathrm{~mL})$ was added to the mixture, and nanoparticles were washed with Milli-Q water on an Amicon ${ }^{\circledR}$ Ultra-15 centrifugal filter device (30k NMWL). A final volume of $3 \mathrm{~mL}$ was evaporated on a rotary evaporator. The remaining nanoparticles were redispersed in an ethanol and diethyl ether mixture $(1: 10 ; 33 \mathrm{~mL})$. The solvent was removed by centrifugation, and the pellet was dried overnight under vacuum.

\section{NPs characterization}

Size distribution of NPs was calculated based on TEM analysis. A drop of NPs $\left(4 \mu \mathrm{L} ; 0.1-0.5 \mathrm{mg} \mathrm{mL}^{-1}\right)$ was deposited onto a 400-mesh carbon-supported copper grid and left to dry. All TEM images were acquired using an FEI TALOS ${ }^{\mathrm{TM}}$ electron microscope with an acceleration voltage of $200 \mathrm{kV}$ equipped with a Ceta CCD camera. Images of the NPs were analyzed using Fiji software, and their diameters were calculated using a homemade script compatible with this software.

${ }^{1} \mathrm{H}-\mathrm{NMR}$ analysis was performed to control the purity of prepared nanoparticles. Assembly of ligands on the nanoparticles causes broadening of their NMR peaks. ${ }^{46-48}$ This effect was used to evaluate the purity of the prepared nanoparticles. The absence of sharp peaks in the NMR spectrum obtained for the solution of nanoparticles suspended in water indicated a lack of impurities, such as unbound ligands. The ratio between ligands in the case of the mixed ligand nanoparticles was assessed by the ${ }^{1} \mathrm{H}-\mathrm{NMR}$ analysis after etching the nanoparticles with iodine. The etching solution was iodine (20 mg) dissolved in methanol-d4 (1 mL). Etching was obtained by suspending NPs $(5 \mathrm{mg})$ in the etching mixture $(0.6 \mathrm{~mL})$ for $30 \mathrm{~min}$ under sonication. The ligand ratio was calculated according to the integrals of the given peaks (Fig. S1 and $\mathrm{S} 2 \dagger)$.

The zeta potentials of nanoparticles were measured in PBS buffer using a Zetasizer Nano ZS (Malvern). The concentration of the nanoparticles was $0.1 \mathrm{mg} \mathrm{mL}^{-1}$.

\section{Preparation of bacteriophages}

Phages were prepared according to a procedure developed by Sambrook et al. ${ }^{49}$ Briefly, the early logarithmic culture of Escherichia coli was infected with bacteriophages. E. coli BL21 was used for the amplification of phages T1, T4, and T7, and E. coli C3000 was used for phages MS2. After lysis, the phages were precipitated by polyethylene glycol precipitation. Collected phages were washed with TM buffer (10 mM TRIS, $\left.10 \mathrm{mM} \mathrm{MgSO}{ }_{4}, 5 \mu \mathrm{M} \mathrm{CaCl}_{2}, \mathrm{pH} 7.4\right)$ on Amicon ${ }^{\circledR}$ Ultra-15 centrifugal filter devices (1000k NMWL) and then dialyzed against TM buffer. After completion of the dialysis, DNase I $(0.2 \mu \mathrm{g}$ $\mathrm{mL}^{-1}$ ) was added to digest the DNA released from the damaged capsids.

\section{Virucidal tests}

Phages were incubated in TM buffer with $0.5 \mathrm{mg} \mathrm{mL}^{-1}$ of nanoparticles at $37^{\circ} \mathrm{C}$ or $50{ }^{\circ} \mathrm{C}$ over three days. The number of active phages was measured at different time points. We used the plaque count method for the determination of bacteriophage activity. Plaque forming units (PFU) can be directly correlated with the number of active phages within the sample. In this approach, the bottom LB-agar medium $(20 \mathrm{~mL})$ was poured onto a plastic Petri dish and left to solidify. Then, the top LB-agar (i.e., LB medium with $0.5 \%$ agar; $4 \mathrm{~mL}$ ) was mixed with an overnight culture of E. coli $(200 \mu \mathrm{L})$ and poured onto the plate. E. coli BL21 was used for phages T1, T4, and T7, and E. coli C3000 was used for phages MS2. 10-fold dilutions of 
phage solution were prepared, and droplets of each dilution $(5 \mu \mathrm{L})$ were spotted onto the top agar layer. Plaques were counted after the incubation of the plates at $37^{\circ} \mathrm{C}$ for $24 \mathrm{~h}$. All experiments were performed in triplicate.

\section{Dose-response tests on phages}

Phages were incubated in TM buffer with various concentrations of nanoparticles at $50{ }^{\circ} \mathrm{C}$ for $24 \mathrm{~h}$. The number of active phages was measured at different time points. As a control, samples with phages without any nanoparticles were used. The number of phages was estimated via the plaque count method described in the previous section. All experiments were performed in duplicate.

\section{Dose-response tests on bacteria}

Inoculum of bacteria $E$. coli BL21 was mixed in LB medium with various concentrations of MUS:OT (85:15) nanoparticles. Then, the growth of the bacterial culture was observed by optical density $\left(\mathrm{OD}_{600}\right)$ measurement. To calculate dose-response, the optical density after $6 \mathrm{~h}$ of incubation was compared. All experiments were performed in triplicate.

\section{Real application test of the infected bacteria-based bioreactor}

First, T1 bacteriophages (200 pfu $\mathrm{mL}^{-1}$ ) were incubated: (a) with MUS : OT $(85: 15)$ nanoparticles $\left(100 \mu \mathrm{g} \mathrm{mL}{ }^{-1}\right)$ at $50{ }^{\circ} \mathrm{C}$ for $1 \mathrm{~h}$, and (b) with MUS : OT (85:15) nanoparticles $(20 \mu \mathrm{g}$ $\mathrm{mL}^{-1}$ ) at $50{ }^{\circ} \mathrm{C}$ for $12 \mathrm{~h}$. Then, to such solutions, an inoculum of bacteria E. coli BL21 in LB medium was added. As controls, samples containing only bacteria (normal bacterial growth) and bacteria with $\mathrm{T} 1$ bacteriophages were prepared. The growth of bacteria was controlled by measuring the optical density $\left(\mathrm{OD}_{600}\right)$, which can be directly correlated with the number of bacteria in the solution. All experiments were performed in four repetitions.

\section{Transmission electron cryo-microscopy}

Phages $\left(\sim 4 \times 10^{10} \mathrm{pfu} \mathrm{mL}^{-1}\right)$ were incubated with nanoparticles $\left(0.1 \mathrm{mg} \mathrm{mL}^{-1}\right)$ in $\mathrm{TM}$ buffer at $37{ }^{\circ} \mathrm{C}$ or $50{ }^{\circ} \mathrm{C}$ for a given amount of time ( $24 \mathrm{~h}$ if not stated otherwise). Then, a droplet of such a solution $(3 \mu \mathrm{L})$ was deposited onto a lacey carbon film grid (Electron Microscopy Sciences, Germany) and blotted to a thin (100-300 nm) layer of liquid. The grid was then immediately flash-frozen in liquid ethane using an FEI Vitrobot Mark IV. Imaging was performed using a Gatan single tilt cryo holder operated on an FEI Tecnai F20 Cryo $80 \mathrm{kV}$ transmission electron microscope in the low-dose mode to visualize the samples at an average exposure of 1-3 electrons $\AA^{-2}$ on a Ceta camera.

\section{Cytotoxicity test}

The toxicity of NPs was examined using MTS [3-(4,5-dimethylthiazol-2-yl)-5-(3-carboxymethoxyphenyl)-2-(4-sulfophenyl)-2Htetrazolium] assay. Vero cell cultures (African green monkey fibroblastoid kidney cells ATCC CCL-81) seeded in 96-well plates were incubated in DMEM (Gibco-BRL, Gaithersburg, MD) supplemented with $2 \%$ FBS with different concentrations of NPs for $24 \mathrm{~h}$. Cell viability was determined using the CellTiter 96 Proliferation Assay Kit (Promega, Madison, WI, USA) according to the manufacturer's instructions. Absorbance was measured using a Microplate Reader (Model 680 , BIORAD) at $490 \mathrm{~nm}$. Cells incubated without nanoparticles were used as the negative control, and cells incubated with $30 \%$ Triton $\mathrm{X}-100$ were treated as the positive control (very high toxicity, no cells survived). The effect on cell viability at different concentrations of NPs was expressed as a percentage of live cells, by comparing the absorbance of treated cells with those of the cells incubated with the culture medium.

\section{Author contributions}

Łukasz Richter: investigation, validation, writing - original draft, visualization, funding acquisition. Karolina Paszkowska: investigation. Urszula Cendrowska: resources, investigation. Francesca Olgiati: resources, investigation. Paulo Jacob Silva: resources. Matteo Gasbarri: resources, visualization. Zekiye Pelin Guven: resources. Jan Paczesny: writing - review \& editing, supervision, methodology. Francesco Stellacci: writing - review \& editing, project administration, funding acquisition, conceptualization.

\section{Conflicts of interest}

There are no conflicts to declare.

\section{Acknowledgements}

This project has received funding from the European Union's Horizon 2020 research and innovation programme under the Marie Skłodowska-Curie grant agreement No. 754462. The work of Ł.R. was supported by Swiss Government Excellence Scholarship. The work of K.P. and J.P. was supported by the National Science Centre within SONATA BIS grant number 2017/26/E/ST4/00041. M.G. was supported by the National Center of Competence in Research (NCCR) Bio-Inspired Materials. The authors are grateful to Professor Marcin Łoś, from the Phage Consultants Company, for his insight into bacteriophages and phage contaminations in the industry. The authors would also like to acknowledge Professor Robert Hołyst from the Institute of Physical Chemistry Polish Academy of Sciences for fruitful discussions and ideas.

\section{References}

1 G. Bogosian, in The Bacteriophages, ed. R. Calendar, Oxford University Press, 2nd edn, 2006, pp. 667-673.

2 M. Łoś, Eur. Biopharm. Rev., 2010, 51, 78-80.

3 E. Jończyk, M. Kłak, R. Międzybrodzki and A. Górski, Folia Microbiol., 2011, 56, 191-200. 
4 Z. Atamer, M. Samtlebe, H. Neve, K. J. Heller and J. Hinrichs, Front. Microbiol., 2013, 4, 1-9.

5 D. M. Guglielmotti, D. J. Mercanti, J. A. Reinheimer and A. del L. Quiberoni, Front. Microbiol., 2012, 2, 1-11.

6 Y. H. Joe, K. Woo and J. Hwang, J. Hazard. Mater., 2014, 280, 356-363.

7 L. Bromberg, D. J. Bromberg, T. A. Hatton, I. Bandín, A. Concheiro and C. Alvarez-Lorenzo, Langmuir, 2012, 28, 4548-4558.

8 T. Matsushita, N. Shirasaki, Y. Matsui and K. Ohno, Chemosphere, 2011, 85, 571-576.

9 A. M. Ledeboer, S. Bezemer, J. J. W. de Haard, I. M. Schaffers, C. T. Verrips, C. van Vliet, E.-M. Düsterhöft, P. Zoon, S. Moineau and L. G. J. Frenken, J. Dairy Sci., 2002, 85, 1376-1382.

10 D. Veesler, B. Dreier, S. Blangy, J. Lichière, D. Tremblay, S. Moineau, S. Spinelli, M. Tegoni, A. Plückthun, V. Campanacci and C. Cambillau, J. Biol. Chem., 2009, 284, 30718-30726.

11 R. D. G. Ferreira, A. R. Azzoni and S. Freitas, Biotechnol. Biofuels, 2018, 11, 81.

12 R. H. Baltz, J. Ind. Microbiol. Biotechnol., 2018, 45, 10031006.

13 A. Murata, K. Kitagawa and R. Saruno, Agric. Biol. Chem., 1971, 35, 294-296.

14 W. Ma, M. Sun, P. Fu, S. Li, L. Xu, H. Kuang and C. Xu, Adv. Mater., 2017, 29, 1703410.

15 H. Zhang, C. Hao, A. Qu, M. Sun, L. Xu, C. Xu and H. Kuang, Angew. Chem. Int. Ed., 2020, 59, 7131-7138.

16 X. Guo, M. Sun, R. Gao, A. Qu, C. Chen, C. Xu, H. Kuang and L. Xu, Angew. Chem. Int. Ed., 2021, 60, 13073-13080.

17 W. Ma, C. Hao, M. Sun, L. Xu, C. Xu and H. Kuang, Mater. Horiz., 2018, 5, 141-161.

18 M. Sun, L. Xu, A. Qu, P. Zhao, T. Hao, W. Ma, C. Hao, X. Wen, F. M. Colombari, A. F. de Moura, N. A. Kotov, C. Xu and H. Kuang, Nat. Chem., 2018, 10, 821-830.

19 L. Xu, M. Sun, P. Cheng, R. Gao, H. Wang, W. Ma, X. Shi, C. Xu and H. Kuang, Adv. Funct. Mater., 2018, 28, 1707237.

20 E. Gilcrease, R. Williams and R. Goel, Water Res., 2020, 181, 115900.

21 K. Gokulan, A. Bekele, K. Drake and S. Khare, Int. J. Nanomed., 2018, 13, 2857-2867.

22 Q. L. Shimabuku, T. Ueda-Nakamura, R. Bergamasco and M. R. Fagundes-Klen, Process Saf. Environ. Prot., 2018, 117, 33-42.

23 B. De Gusseme, L. Sintubin, L. Baert, E. Thibo, T. Hennebel, G. Vermeulen, M. Uyttendaele, W. Verstraete and N. Boon, Appl. Environ. Microbiol., 2010, 76, 10821087.

24 Q. L. Shimabuku, F. S. Arakawa, M. Fernandes Silva, P. Ferri Coldebella, T. Ueda-Nakamura, M. R. FagundesKlen and R. Bergamasco, Environ. Technol., 2017, 38, 20582069.

25 J. M. Mazurkow, N. S. Yüzbasi, K. W. Domagala, S. Pfeiffer, D. Kata and T. Graule, Environ. Sci. Technol., 2020, 54, 1214-1222.
26 V. I. Syngouna and C. V. Chrysikopoulos, J. Colloid Interface Sci., 2017, 497, 117-125.

27 M. Cho, E. L. Cates and J.-H. Kim, Water Res., 2011, 45, 2104-2110.

28 R. Cheng, M. Kang, S. Zhuang, S. Wang, X. Zheng, X. Pan, L. Shi and J. Wang, Sci. Total Environ., 2019, 649, 9951003.

29 E. Sánchez-López, D. Gomes, G. Esteruelas, L. Bonilla, A. L. Lopez-Machado, R. Galindo, A. Cano, M. Espina, M. Ettcheto, A. Camins, A. M. Silva, A. Durazzo, A. Santini, M. L. Garcia and E. B. Souto, Nanomaterials, 2020, 10, 292.

30 V. Cagno, P. Andreozzi, M. D’Alicarnasso, P. J. Silva, M. Mueller, M. Galloux, R. Le Goffic, S. T. Jones, M. Vallino, J. Hodek, J. Weber, S. Sen, E. R. Janecek, A. Bekdemir, B. Sanavio, C. Martinelli, M. Donalisio, M. A. R. Welti, J. F. Eleouet, Y. Han, L. Kaiser, L. Vukovic, C. Tapparel, P. Král, S. Krol, D. Lembo and F. Stellacci, Nat. Mater., 2018, 17, 195-203.

31 M. N. Baeshen, A. M. Al-Hejin, R. S. Bora, M. M. M. Ahmed, H. A. I. Ramadan, K. S. Saini, N. A. Baeshen and E. M. Redwan, J. Microbiol. Biotechnol., 2015, 25, 953-962.

32 C.-J. Huang, H. Lin and X. Yang, J. Ind. Microbiol. Biotechnol., 2012, 39, 383-399.

33 N. A. Baeshen, M. N. Baeshen, A. Sheikh, R. S. Bora, M. M. M. Ahmed, H. A. I. Ramadan, K. S. Saini and E. M. Redwan, Microb. Cell Fact., 2014, 13, 141.

34 M. Los, in Microbial Metabolic Engineering: Methods and Protocols, Springer, New York, NY, 2012, pp. 305-315.

35 M. L. Yap and M. G. Rossmann, Future Microbiol., 2014, 9, 1319-1327.

36 H.-W. Ackermann, D. Tremblay and S. Moineau, World Fed. Cult. Collection Newslett., 2004, 38, 35-40.

37 M. H. Ly-Chatain, S. Moussaoui, A. Vera, V. Rigobello and Y. Demarigny, Front. Microbiol., 2013, 4, 1-6.

38 A. Ortega, S. Farah, P. Tranque, A. V. Ocaña, S. H. NamCha, N. Beyth, C. Gómez-Roldán, R. Pérez-Tanoira, A. J. Domb, F. C. Pérez-Martínez and J. Pérez-Martínez, IET Nanobiotechnol., 2015, 9, 342-348.

39 P. G. Leiman, S. Kanamaru, V. V. Mesyanzhinov, F. Arisaka and M. G. Rossmann, Cell. Mol. Life Sci., 2003, 60, 23562370.

40 I. Gitlin, J. D. Carbeck and G. M. Whitesides, Angew. Chem., Int. Ed., 2006, 45, 3022-3060.

41 European Commission EUROSTAT, Nat. Methods, 2008, 5, 135-146.

42 U. Cendrowska, P. J. Silva, N. Ait-Bouziad, M. Müller, Z. P. Guven, S. Vieweg, A. Chiki, L. Radamaker, S. T. Kumar, M. Fändrich, F. Tavanti, M. C. Menziani, A. Alexander-Katz, F. Stellacci and H. A. Lashuel, Proc. Natl. Acad. Sci. U. S. A., 2020, 117, 6866-6874.

43 Z. P. Guven, P. H. J. Silva, Z. Luo, U. B. Cendrowska, M. Gasbarri, S. T. Jones and F. Stellacci, J. Visualized Exp., 2019, 2019, 1-11.

44 N. Zheng, J. Fan and G. D. Stucky, J. Am. Chem. Soc., 2006, 128, 6550-6551. 
45 A. Verma, O. Uzun, Y. Hu, Y. Hu, H.-S. Han, N. Watson, S. Chen, D. J. Irvine and F. Stellacci, Nat. Mater., 2008, 7, 588-595.

46 A. Badia, W. Gao, S. Singh, L. Demers, L. Cuccia and L. Reven, Langmuir, 1996, 12, 1262-1269.

47 L. E. Marbella and J. E. Millstone, Chem. Mater., 2015, 27, 2721-2739.
48 M. J. Hostetler, J. E. Wingate, C.-J. Zhong, J. E. Harris, R. W. Vachet, M. R. Clark, J. D. Londono, S. J. Green, J. J. Stokes, G. D. Wignall, G. L. Glish, M. D. Porter, N. D. Evans and R. W. Murray, Langmuir, 1998, 14, 17-30.

49 J. Sambrook, E. F. Fritsch and T. Maniatis, Molecular Cloning - A Laboratory Manual, Cold Spring Harbor Press, Cold Spring Harbor, 2nd edn, 1989. 